\title{
Lessons on Gender Responsive Governance Gleaned From the Nature and Focus of a University Community Extension Program
}

Leodinito Yongco Cañete*

Cebu Normal University, Cebu City, Cebu, Philippines

\begin{abstract}
Cebu Normal University has a robust approach to its extension services. Eight extension projects were subjected to ex post facto evaluation to determine whether they have achieved their goals vis-a-vis the UNDP governance framework. The main objective of the evaluation was to construct a nature-focus paradigm for the extension services function of Philippine state universities and colleges to optimize the use of their limited resources. The current naturefocus of all eight extension projects point to a non-optimal pedagogy, andragogy - community service combination because it reflects a specification-led and output-driven type of extension project. Future extension projects have to incorporate the UNDP governance framework that optimizes relationships between their nature and focus with lesser actual time spent in the field and more community empowerment by catalyzing change.
\end{abstract}

Keywords: Gender and development; Extension;community; Empowerment; University

\section{Introduction}

Extension service is a major final output of state-funded universities and colleges in the Philippines. It covers the dissemination of the research outputs for the use and benefit of the community of locality in which the SUC is located. Cebu Normal University, a state-funded university in Central Philippines, has a robust approach to its extension services to ensure that it provides relevant and responsive community service that is expected to result in tangible and measurable changes in the welfare of local communities. The university's extension service is lumped into a program that has five interdisciplinary components in education, health, environment, livelihood and peace and goes by the name of E-HELP. These components reflect the strengths and capacities of CNU faculty and staff as part-time extension workers [1]. CNU's current president, defined the role of the university's faculty and staff to collectively and creatively share their knowledge and resources to local communities and to share in the journey out of poverty and into a life of improved chances and happiness [1].

From 2010 to 2012, eight projects were implemented to jointly and innovatively respond to the interrelated issues on education, health, environment, livelihood, and peace as gleaned in Caputatan Norte, a rural village in Medellin, situated in the northern tip of the island of Cebu. Its population in 2010 was estimated at 2,520 scattered over an area of a little less than 1,000 hectares. The villagers' main source of income comes from seasonal work in the sugarcane plantations which hover between P1,500 to P3,000 per month. CNU has a campus in Medellin, Cebu.

$\mathrm{CNU}$ as a public higher education institution has to strengthen gender equality, development, and peace in its locality by reiterating the importance of the strategic role of higher education in capacity building and empowerment of women through appropriate gender and development activities and to develop and maintain gender and development (GAD) projects that would effectively assist the constituencies of the localities where it is situated. However, CNU faces several challenges in the promotion of gender-responsive governance particularly in establishing and maintaining an enabling environment for development wherein the interaction between the government, the private sector, and civil society is fundamental.

The Philippines is one of the top ten countries in the world with the smallest gender gap due to the number of years a female has been its head of state. A female president, however, does not automatically result in gender equality or guarantee that the government has a stronger focus on gender equality. A pressing need is to strengthen accountable and gender-responsive governance. Thus, national government agencies and local government units must allocate funds to implement their gender projects such as providing health services, advocacy and information dissemination on gender issues, establishing or improving service facilities for women, establishing databases and mechanisms for reporting on gender issues, and revising textbooks to remove social and gender stereotypes. These projects encounter technical difficulties and political issues in trying to allocate funds. But a number of success stories exist.

This documentary evaluation of CNU's E-HELP program as implemented in Caputatan Norte from 2010 to 2012 gathered and integrated various data to show the value of the program to the GAD initiatives of the university. The summative examination was conducted to determine whether its achieved outputs correspond to gender-responsive governance under the Philippine Framework Plan for Women which describes gender-responsive governance is one that enhances the abilities of women and men to contribute and benefit from development. The evaluation framework considers the services delivered and the outputs gained collectively for all the eight projects as they affect the local community efforts to optimize the interaction between the public and private sectors to achieve social and economic development (Figure 1).

The illustration, which was adapted from the Six Steps to Effective Evaluation: A handbook for program and project managers of the UK Joint Information Systems Committee published by [2], shows

*Corresponding author: Leodinito Yongco Cañete, Cebu Normal University, Cebu City, Cebu, Philippines; Tel: +6332-2369795; E-mail: leodican@yahoo.com

Received January 06, 2014; Accepted February 13, 2014; Published February 20, 2014

Citation: Cañete LY (2014) Lessons on Gender Responsive Governance Gleaned From the Nature and Focus of a University Community Extension Program. J Glob Econ 2: 109. doi:10.4172/2375-4389.1000109

Copyright: @ 2014 Cañete LY. This is an open-access article distributed unde the terms of the Creative Commons Attribution License, which permits unrestricted use, distribution, and reproduction in any medium, provided the original author and source are credited. 


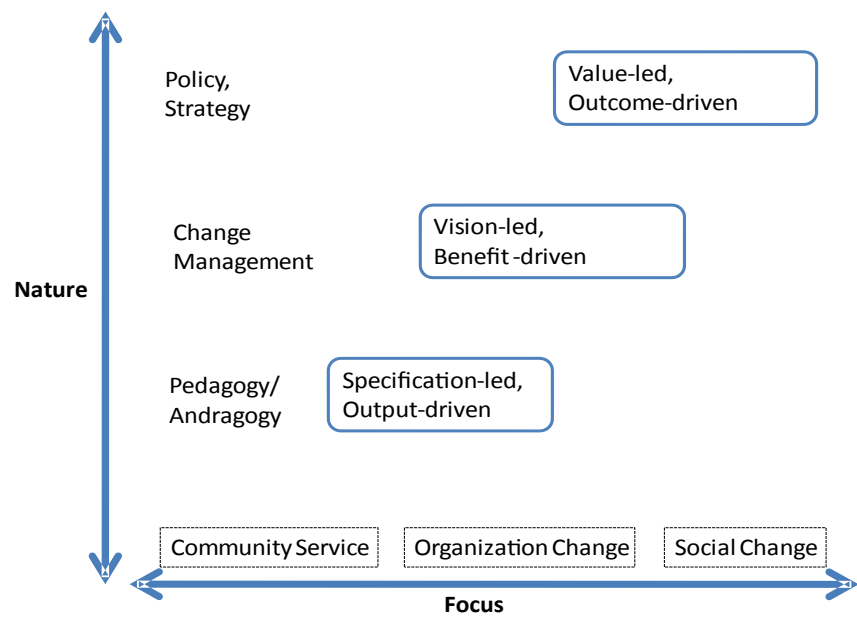

Figure 1: Nature-Focus Characteristics of Extension Projects (Illustration).

the relationship between the focus of extension projects which may begin with community service, progress into organizational change and culminate in societal change. The nature of extension projects may take the beginning form of pedagogy/andragogy, moving into change management with policy, strategy in the apex. The combination of the nature and focus of these projects results in three major characteristics: specification-led, output-driven; vision-led, benefit-driven; and visionled, outcome-driven.

The main objective of this evaluation was to construct a naturefocus paradigm for the extension services function of Philippine state universities and colleges to optimize gender-responsive governance in local communities that they serve. Specifically, it aimed to classify the CNU E-HELP projects based on the nature-focus paradigm.

\section{Methodology}

The study is mainly a documentary evaluation of CNU's E-HELP program as implemented in Caputatan Norte from 2010 to 2012. It gathered and integrated various evaluation data that showed the value of the program to the GAD initiatives of the university. Focus group discussions were conducted last August 2012 to solicit inputs from extension services beneficiaries to determine whether the projects achieved outputs correspond to gender-responsive governance under the Philippine Framework Plan for Women which describes genderresponsive governance is one that enhances the abilities of women and men to contribute and benefit from development.

The FGDs covered the services delivered and the outputs gained collectively for all the eight projects as they affect the local community efforts to optimize the interaction between the public and private sectors to achieve social and economic development. Copies of the evaluation of each extension project were also examined. The evaluation sheets contained the comprehensive list of services and their mode of delivery. The services reflected the focus of the projects while the mode of delivery provided insights in the nature of the projects. The evaluation also provided evidence on how the projects were implemented as basis for determining whether to do things differently, to do different things, or to do things that will influence others to change.

The following E-HELP projects are included: Caputatan Instruction Intervention Project, CNU Team Support to CNES Teachers, Science and Math Made Easy, and KABATAAN. The health projects are
Community HeAL Center and Operation Pansayan. Homegrown Recipe for Survival covers livelihood and environment and Adventure Therapy for Out-of-School Youth is for the peace component.

\section{Related Literature}

In mainstreaming gender and development efforts, the Philippine government has undertaken a number of reforms for decentralizing urban governance and increasing the role of community-based organizations (CBOs) and non-governmental organizations in urban policy and program development and implementation [3]. Shatkin further argues that the decentralization efforts reflect the interests of a variety of politically powerful social groups, including not only organizations of civil society, but also local political families and international and domestic business interests found out that in recent years. In addition, lack of local government capacity in many cities and municipalities and the existence of powerful economic interests at the local level that compete with civil society organizations for influence continue to inhibit meaningful civil society participation.

The development and maintenance of viable urban poor communities advances effectively when people participate and exercise significant control over the decisions affecting their lives as clarified by Mary [4]. Through effective community organizing, drawing on the support of active NGOs and on alliances with experienced people's organizations, urban poor communities are able to plan, carry out wide-ranging local improvements, and articulate their ideas. They are even better served if government and private authorities listen seriously to their views and adopt a participatory mode of working together. This corresponds to accepted management theory and practice that those closest to the problem are best able to solve it.

In the Philippines where gender inequality is still manifested there is a pressing need is to strengthen accountable and gender-responsive governance so that that those closest to the problems may be able to solve them. National government agencies and local government units therefore need to distribute funds to implement gender and development projects that promote gender equality through health services, advocacy and information dissemination on gender issues, establishing or improving service facilities for women, establishing databases and mechanisms for reporting on gender issues, and revising textbooks to remove social and gender stereotypes.

But communities need to be organized to ensure successful delivery of these needed and vital services. Peter [5] Identified the following factors that lead to successful community organizing. Community organizing, community-based development and community-based service provision are distinct community empowerment strategies. Community organizing efforts focus on mobilizing residents to address common problems. Leadership development, strategic planning, and network building (across neighborhoods, cities, and regions) are necessary to mobilize people to solve their common problems. The major obstacle to successful community organizing is the lack of training in leadership development and organizational capacity building. The primary strategy recommended for overcoming this obstacle is to help community organizations take advantage of intermediary organizations such as organizing networks and training centers that have emerged during the past several decades.

While community empowerment is central to community development, making this concept operational in a program context remains elusive according to Laverack [6]. Laverack [7] revealed that (1) participation; (2) community-based organizations; (3) local leadership; (4) resource mobilization; (5) asking 'why'; (6) assessment of problems; 
(7) links with other people and organizations; (8) role of outside agents; and (9) program management can lead to an improvement in the health status of an individual, group, or community.

The literature point out that community development projects need to do things differently, to do different things, or to do things to influence others to accept the tenets of gender and development promoted by UNDP [8]. Since governance comprises the mechanisms, processes and institutions, through which citizens and groups articulate their interests, exercise their legal rights, meet their obligations and mediate their differences, it needs to be gender responsive so that decisions are reached based on broad consensus.

\section{Results}

Each extension project is briefly described followed by a comprehensive list of services rendered to reflect the focus and mode of delivery for services to determine its nature. The projects are ordered according to the discipline components of E-HELP. For education, the following projects are included: Caputatan Instruction Intervention Project, CNU Team Support to CNES Teachers, Science and Math Made Easy, and KABATAAN The health projects are Community HeAL Center and Operation Pansayan. Homegrown Recipe for Survival covers livelihood and environment and Adventure Therapy for Out-of-School Youth is for the peace component.

Caputatan Instructional Intervention Project (CIIP): Earning High School Certificate through Accreditation and Equivalency was designed to help out-of-school youth who have dropped out of formal school earn and complete high school certificate by providing them instruction in math, science, English, Filipino, and social studies competencies over a period of 20 four-hour sessions conducted on Fridays (Table 1).

CNU Team Support Program for Caputatan Norte Elementary School Teachers was proposed to provide a comprehensive, responsive, and sustained professional development process through mentoring to arrest the reported low achievement levels of the students. The ten once-a-week contacts between the CNU faculty and CNES teachers provided structured and non-structured sessions for empathy and encouragement, comments and constructive criticism, coaching on appropriate teaching strategies, theories and practices of pedagogy, and material support in constructing and developing learning materials (Table 2).

Science and Math Made Easy was designed to improve the low performance of CNES pupils in the Regional Achievement Test through innovative learning strategies that present math and science knowledge over 16 Fridays from December 2010 to March 2011 (Table 3).

KABATAAN stands for Kaugmaonsa Bata AtungAtimanun (Caring for Children's Future) was intended to provide schoolreadiness to children aged four to six years old from eleven sitios of Caputatan Norte conducted four-hour sessions every Friday in two sites (Bangon and Ybañez) from July 2010 to March 2011 (Table 4).

The Community Health Access and Learning (HeAL) center was proposed to respond to the needs of the community for quality and affordable generic medicines including basic health services such as blood pressure reading, blood sugar testing, asthma nebulization, vaccination and information, education, and communication (IEC) activities. The project ran from November 2010 to March 2012. The project established one botikasa barangay in sitioYbañez that is still operational (Table 5).
Operation Pansayan (toilet) is a community-wide participatory action project that installed eleven toilets (one per sitio) in Caputatan Norte (Table 6).

Homegrown Recipe for Survival was designed to introduce biointensive gardening techniques to seven community leaders who established their own plots in areas surrounding the barangay center. The plant varieties included vegetables, fruit trees, ornamentals and deciduous species (Table 7).

Adventure Therapy for Out-of-School Youth was proposed to provide psychosocial services, specifically gestalt-oriented adventure activities for 109 out-of-school youth which included those who participated in the CIIP in eight weekend sessions from July 2010 to March 2011 (Table 8).

\section{Discussion}

The nature of the eight projects show the following pedagogic/

\begin{tabular}{|l|l|}
\hline \multicolumn{1}{|c|}{ Nature } & \multicolumn{1}{c|}{ Focus } \\
\hline & - basic education competencies in math \\
- assessment & - basic education competencies in science \\
- instruction & - basic education competencies in English \\
& - basic education competencies in Filipino \\
\hline & basic education competencies in social studies \\
\hline
\end{tabular}

Table 1: Earning High School Certificate through Accreditation and Equivalency.

\begin{tabular}{|l|l|}
\hline \multicolumn{1}{|c|}{ Nature } & \multicolumn{1}{c|}{ Focus } \\
\hline - assessment & - performance indicators \\
- training & - instructional materials \\
& - classroom management \\
& - teachers' roles and responsibilities \\
\hline
\end{tabular}

Table 2: Low achievement levels of the students.

\begin{tabular}{|l|l|}
\hline \multicolumn{1}{|c|}{ Nature } & \multicolumn{1}{c|}{ Focus } \\
\hline - needs assessment & module development \\
- teaching & - science competencies for grades III and VI \\
mathematics competencies for grades III and VI
\end{tabular}

Table 3: Low performance of CNES pupils.

\begin{tabular}{|l|l|}
\multicolumn{1}{|c|}{ Nature } & \multicolumn{1}{c|}{ Focus } \\
- $\begin{array}{l}\text { assessment } \\
\text { teaching/coaching }\end{array}$ & - identity formation \\
child-caregiving & personal grooming and hygiene \\
\hline
\end{tabular}

Table 4: school-readiness to children aged four to six years old.

\begin{tabular}{|l|l|}
\hline \multicolumn{1}{|c|}{ Nature } & \multicolumn{1}{c|}{ Focus } \\
\hline - training & . basic pharmacology \\
- procurement of medicines & - $\begin{array}{l}\text { diagnosing common illnesses } \\
\text { - elementary accounting and bookkeeping }\end{array}$ \\
\hline
\end{tabular}

Table 5: one botika sa barangay in sitio Ybañez.

\begin{tabular}{|l|l|}
\hline \multicolumn{1}{|c|}{ Nature } & \multicolumn{1}{c|}{ Focus } \\
\hline - health information dissemination & - designing and costing toilet facilities \\
- training & - hygiene and sanitation \\
- spot mapping & - foecal-oral infections \\
\hline
\end{tabular}

Table 6: Operation Pansayan.

\begin{tabular}{|l|l|}
\hline \multicolumn{1}{|c|}{ Nature } & \multicolumn{1}{c|}{ Focus } \\
\hline - survey & - bio-intensive gardening \\
- nursery construction & - species identification \\
- tranting and cultivation & - fertilizers \\
\hline
\end{tabular}

Table 7: Introduce bio-intensive gardening techniques. 


\begin{tabular}{|l|l|}
\hline \multicolumn{1}{|c|}{ Nature } & \multicolumn{1}{c|}{ Focus } \\
\hline - assessment & - experiential counseling \\
- convle development & - psychotherapy \\
- training & lectures on mental hygiene, domestic violence, \\
- intervention & $\begin{array}{l}\text { drug dependency, alcoholism, juvenile issues and } \\
\text { personality development }\end{array}$ \\
\hline
\end{tabular}

Table 8: Adventure Therapy for Out-of-School Youth was proposed to provide psychosocial services.

andragogic characteristics: assessment, instruction, remediation, coaching, training, module development, teaching/coaching, childcaregiving, construction, procurement of medicines, inventory, health information dissemination, consultation, spot mapping, survey, planting and cultivation, convocation, intervention. The focus of the eight projects cover the following aspects: basic education competencies in math, science, English, Filipino, social studies, performance indicators, instructional materials, classroom management, teachers' roles and responsibilities, identity formation, personal grooming and hygiene, food as sustenance, basic pharmacology, diagnosing common illnesses, elementary accounting and bookkeeping, designing and costing toilet facilities, hygiene and sanitation, foecal-oral infections, bio-intensive gardening, species identification, fertilizers, pesticides, experiential counseling, psychotherapy, and lectures on mental hygiene, domestic violence, drug dependency, alcoholism, juvenile issues and personality development.

The current nature-focus of all eight extension projects point to a pedagogy, andragogy - community service combination which is the basic a non-optimal combination. This combination reflects a specification-led and output-driven type of extension project. All eight projects mainly responded to the specifications listed in their proposal which emphasizes the attainment of listed outputs at the terminal stage. However, the projects provided opportunities for both the public and private sectors to intersect as evidenced by their wide community participation, transparent and accountable delivery mechanisms, and effective and equitable service.

Future extension projects of CNU have to move from its current state to a nature of change management and focus on organizational change which is vision-led and benefits-driven. The optimum nature- focus combination calls for policy, strategy combined with societal change which is vision-led and outcomes-driven. This optimum combination maximizes the exercise of economic, political and administrative authority to manage their community affairs at all levels because all constituents can articulate their interests, exercise their legal rights, meet their obligations and mediate their differences.

\section{Conclusions}

The CNU E-HELP program as implemented in Caputatan Norte, Medellin is full learning experiences that can guide extension programs of public higher education institutions with similar conditions. Future extension projects have to incorporate the UNDP governance framework that optimizes relationships between their nature and focus with lesser actual time spent in the field and more community empowerment by catalyzing change. Furthermore, proposed projects have to promote gender-responsive governance which enhances the abilities of women and men to contribute and benefit from development.

\section{References}

1. Lopez, Marcelo T (2009) “E-HELP: CNU's Integrated Community Extension Program" in EHELP: Protecting the Poor from Pressures of Poverty unpublished brochure by Cebu Normal University.

2. Asian Development Bank (2008) Paradox and Promise in the Philippines: A Joint Country Gender Assessment.

3. Shatkin G (2000) Obstacles to Empowerment: Local Politics and Civil Society in Metropolitan Manila, the Philippines. Urban Studies 37: 2357-2375.

4. Mary R (2000) Community Empowerment, People's Organizations, and the Urban Poor: Struggling for Shelter, Infrastructure, Services, and Dignity in the Philippines.

5. Peter D (1996) Community Empowerment Strategies: The Limits and Potentia of Community Organizing in Urban Neighborhoods. Cityscape 2: 121-159.

6. Laverack $G$ (2001) An identification and interpretation of the organizational aspects of community empowerment. Community Dev J 36: 134-145.

7. Laverack G (2006) Improving Health Outcomes through Community Empowerment: A Review of the Literature. J Health Popul Nutr 24: 113-120.

8. UNDP (1997) Governance for sustainable human development 